\title{
MEASUREMENT OF THREE-DIMENSIONAL TEMPERATURE FIELDS ABOVE HEATED SURFACES BY HOLOGRAPHIC INTERFEROMETRY
}

\author{
D. W. SWEENEY* and C. M. VEST \\ Department of Mechanical Engineering, The University of Michigan, Ann Arbor, Michigan, U.S.A.
}

(Received 10 December 1973 and in revised form 20 March 1974)

\begin{abstract}
Optical holography can be used to record multi-directional interferometric data, which provides a basis for measuring three-dimensional, asymmetric temperature or density fields in fluids. If continuous optical pathlength data are available over a $180^{\circ}$ angle of view, the temperature or density field is shown to be equal to the inverse Radon transform of the data. A procedure for computing limited-resolution reconstructions of the field in terms of discrete data collected over a limited angle of view is presented.

The technique of holographic interferometry was used to map isothermal contours in the developing convective plume above heated, horizontal, rectangular surfaces. It was found that the thermal structure of the developing plume is strongly influenced by the partitioning of the flow adjacent to the surface along lines of geometric symmetry.
\end{abstract}

\section{NOMENCLATURE}

$a_{m n}, \quad$ series coefficient, equation (3);

$f$, refractive index change, equation (1);

$\bar{f}, \quad$ approximate refractive index change, equation (8);

$F_{m n}$, generating function, equation (3);

$g$, gravitational acceleration;

$l_{x}, l_{y}$, grid spacing;

$L, \quad$ width of plate;

$n$, refractive index;

$P, \quad$ coordinate, Fig. 7;

$r, \quad$ coordinate, Fig. 7;

$R a, \quad$ Rayleigh number;

$S_{k}$, length of optical ray;

$T_{s}$, temperature of plate surface;

$T$, temperature of ambient fluid;

$U_{o}$, object wavefront of laser light;

$U_{R}$, reference wavefront of laser light;

$x, y, \quad$ coordinates, Fig. 7 .

\section{Greek symbols}

$\beta, \quad$ thermal expansivity;

$\theta_{j}, \quad$ coordinate, Fig. 2;

$\kappa, \quad$ thermal diffusivity;

$v$, kinematic viscosity;

$\xi$, coordinate, Fig. 7;

$\rho_{i}, \quad$ coordinate, Fig. 2;

$\phi, \quad$ coordinate, Fig. 7;

$\Phi$, optical pathlength function;

$\psi$, coordinate, Fig. 7.

*Present address: School of Mechanical Engineering, Purdue University, Lafayette, Indiana, U.S.A.

\section{INTRODUCTION}

OptiCAL methods such as Mach-Zehnder interferometry and schlieren photography (cf. Hauf and Grigul [1]) are of great utility for visualizing temperature or density fields in forced and free convection, high-speed aerodynamic flows, and plasmas, where the insertion of probes may disrupt the flow, or where point-by-point measurements are impractical. These classical optical methods can also be used to make quantitative measurements of such fields, but only if they have radial symmetry or are essentially two dimensional. It would therefore be desirable to devise an optical method whereby three-dimensional, asymmetric temperature or density fields can be measured. Such a method is described in this paper. It requires multi-directional interferometric data, which is obtained by using optical holography. The problem of inverting this data to determine a temperature field has analogs in the fields of X-ray analysis, electron microscopy and radio astronomy, and has been solved previously for the case in which continuous data are available over a $180^{\circ}$ range of viewing angle [2-6].

In this paper, we present a method for inverting discrete multidirectional interferometry data for the practical case in which the range of viewing angle is restricted. In order to demonstrate both the experimental technique and the method of data inversion, the temperature field in the steady natural convective plume a short distance above a heated, horizontal, rectangular plate was measured. These experiments establish the feasibility of using holographic interferometry to measure three-dimensional, asymmetric temperature fields, and are indicative of the potential 
importance of this technique for heat- and masstransfer experimentation.

The possibility of applying optical holography to interferometry was first suggested by Horman [7]. Heflinger, Weurker and Brooks [8] reported the first diffuse-illumination interferograms of transparent objects, and indicated their potential usefulness for aerodynamic studies. A few measurements of temperature fields have been reported for situations in which classical interferometry could have been used, but for which holographic interferometry presented experimental advantages. Aung and O'Reagan [9] recently described an experiment of this type and discussed the experimental advantages. Alwang et al. [2] reported the first measurement of an asymmetric temperature field - that in a slot flame. Matulka and Collins [10] reported successful density measurements in a slightly asymmetric air jet. The present study significantly differs from these in regard to the type and generality of the data analysis technique, particularly in that a $180^{\circ}$ range of viewing angle is not required.

\section{HOLOGRAPHIC INTERFEROMETRY}

In order to measure three-dimensional, asymmetric temperature fields it is necessary to make multidirectional measurements of optical pathlength through the medium under study. Figure 1 is a schematic diagram of a holographic interferometer suitable for this purpose. It utilizes the off-axis technique developed by Leith and Upatnieks [11]. An object wavefront $U_{o}$ of laser light can be "recorded" by adding to it a coherent reference wavefront $U_{R}$ and photographing the resulting intensity pattern in a plane denoted by $(x, z)$. If the photographic plate (hologram) is developed

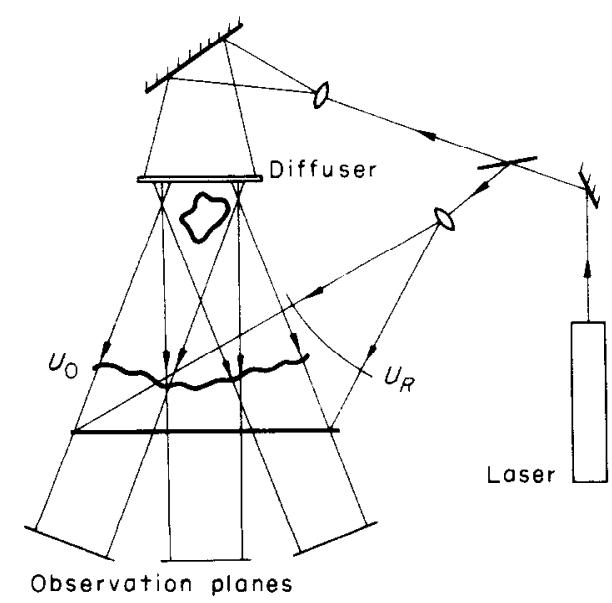

FIG. 1. Holographic interferometer in which a diffuse wave traverses the object; this interferogram can be viewed from many directions. and later illuminated by $U_{k}(x, z)$, it acts as a complex diffraction grating from which emanates a fully detailed replica of $U_{0}(x, z)$. The reader may refer to monographs such as that by Collier, Burckhardt and Lin [12] for a detailed account of optical holography.

Since the holographic rccording process is essentially linear. two wavefronts, $U_{n}$ and $U_{0}^{\prime}$. can be recorded sequentially in time on a single hologram. In the experiments described in this paper, $U_{n}$ is an optical wavefront which has passed through an isothermal fluid. and $U_{0}^{\prime}$ is an initially identical wavefront which has passed through the same fluid after steady natural convection has been established. The sequential recordings of $U_{0}$ and $U_{o}^{\prime}$ are made on a single hologram plate which remains in a fixed position during the experiment. When this plate is properly developed and reilluminated with $U_{R}, U_{o}$ and $U_{o}^{\prime}$ are simultaneously reconstructed, yielding an intensity at an observation plane which is proportional to $\left|U_{o}+U_{o}^{\prime}\right|^{2}$. This represents the intensity distribution $\left|U_{\theta}\right|^{2}$ with a superimposed pattern of interference fringes, which constitute the interferometric data. The key to the present application is the high information content of the hologram, which permits the recording of wavefronts of virtually unlimited complexity. For example, a diffuser such as a plate of opal glass [8], or a phase grating $[13,14]$, can be placed behind the test section. The resulting hologram can be observed from various directions compatible with the apertures of the hologranl and diffuser or grating, thereby providing interferometric data for a collection of rays which traverse the object field in many different directions. It is this multi-directional data which makes it possible to reconstruct an asymmetric refractive index field, by methods described in the next section.

\section{DATA ANALYSIS}

The data provided by interferometry is a fringc pattern from which a pathlength function can be defined. The objective of the data analysis is to invert this function in order to deduce the refractive index distribution, which is simply related to the temperature field. If a holographic interferogram is viewed in a direction parallel to the $y$-dxis, the pathlength function is defined by

$$
\Phi(x, z)=\int f(x, y, z) \mathrm{d} y .
$$

$f(x, y, z)=n(x, y, z)-n_{0}$ is the refractive index relative to $n_{0}$, its value at the time of the initial holographic exposure, $\mathrm{d} y$ is the differential length of the ray, and the integration is across the entire object field. In classical interferometers, such as the Mach-Zehnder, only a single plane wave of light passes through the fluid. In this case, equation (1) can be inverted only 
if the field does not vary in the $y$-direction, or if the field is radially symmetric (cf. [1]). When multidirectional holographic interferometry is used the temperature field must be determined from pathlength functions which are known for optical rays passing through the fluid in many different directions. In the following discussion, it is assumed that refraction is negligible, so that these rays remain essentially straight lines. Measurements can then be made independently in individual planes, $z=$ constant.

Prior to developing a practical computational scheme for evaluation of experimental data, it is desirable to demonstrate the existence of a formal mathematical solution to the underlying problem of determining $f(x, y)$ from the values of its integrals along a collection of straight lines traversing the field in various directions. This is done in the Appendix, where it is shown that if continuous data are available for all possible rays through the field, then

$$
f(r, \phi)=\frac{1}{2 \pi^{2}} \int_{-\pi / 2}^{\pi / 2} \mathrm{~d} \psi \int_{-\infty}^{\infty} \frac{(\partial \Phi / \partial p) \mathrm{d} p}{r \sin (\phi-\psi)-p} .
$$

The nomenclature for equation (2) is indicated in Fig. 7.

An analysis scheme applicable to discrete data must be developed for experimental applications. Sweeney [15] conducted simulated interferometry experiments using a digital computer and found that numerical evaluation of equation (2) using discrete input data yields accurate reconstructions of $f(r, \phi)$. He noted that the apparent singularity when $p=r \sin (\phi-\psi)$ does not cause the integral in equation (2) to diverge if $\partial^{2} \Phi / \partial p^{2}$ is finite everywhere. This condition, which is necessary for successful inversion of data, would be met in any experiment in which useful interferometric data could be obtained.

An alternative to direct application of equation (2) is to use a series representation of the field,

$$
f(x, y)=\sum_{m=1}^{\infty} \sum_{n=1}^{\infty} a_{m n} F_{m n}(x, y),
$$

where the $F_{m n}$ form an appropriate set of generating functions. It is required that each $F_{m n}$ be explicitly integrable along arbitrary lines through the field. Appropriate generating functions have been given previously by Cormack $[4,5]$, and Maldonado and Olsen [16] in other physical contexts. Matulka and Collins [10] have used the series of Maldonado and Olsen to analyze multi-directional interferometric data. These methods require that data be obtained over a complete $180^{\circ}$ range of viewing angle, since the series coefficients are determined by orthogonalization. This restriction, which also applies to equation (2), is severe because optical system constraints, finite aperture test section windows, and opaque objects in the ficld of vicw may make such data unobtainable.
The present authors have explored the accuracy and computational efficiency of several techniques by which approximate determinations of $f(x, y)$ can be obtained using discrete data collected over a limited range of viewing angle [17]. One of these methods, which was selected for use in the experiments reported here, is described below.

In discrete form, the integral equation governing multi-directional interferometry is replaced by a set of integral equations,

$$
\int_{S_{k}} f(x, y) \mathrm{d} S_{k}=\Phi_{k}
$$

where $\mathrm{d} S_{k}$ is the differential length of the $k$ th ray and $\Phi_{k}$ is its optical pathlength across the field. If the bandwidths of the Fourier transform of $f(x, y)$ are finite and denoted by $B_{x}$ and $B_{y}$, then according to the Whittaker-Shannon sampling theorem (Peterson and Middleton [18]), $f(x, y)$ can be represented by

$$
\begin{aligned}
& f(x, y)=\sum_{m=-\infty}^{\infty} \sum_{n=-\infty}^{\infty} f\left(\frac{m}{2 B_{x}}, \frac{n}{2 B_{y}}\right) \\
& \quad \times \operatorname{sinc}\left[2 B_{x}\left(x-\frac{m}{2 B_{x}}\right)\right] \operatorname{sinc}\left[2 B_{y}\left(y-\frac{n}{2 B_{y}}\right)\right] .
\end{aligned}
$$

Sinc $x=(\sin \pi x) /(\pi x)$, and the coefficients in this series are the values of $f(x, y)$ at a discrete set of sample points separated by distances $1 / 2 B_{x}$ and $1 / 2 B_{y}$ in the $x$ and $y$ directions respectively. In real applications, reasonable effective bandwidths $B_{l x}$ and $B_{l y}$, can often be assigned

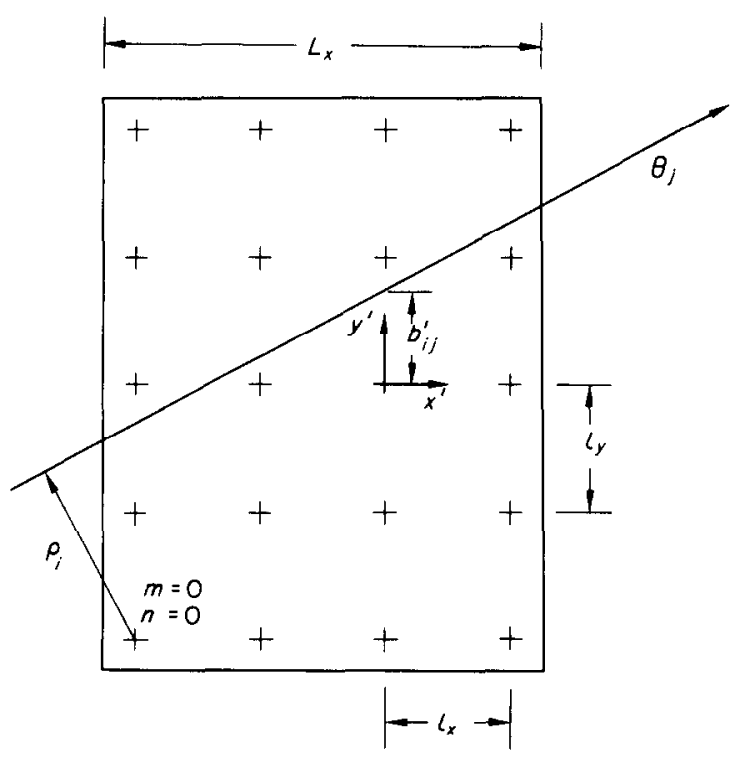

FIG. 2. Nomenclature for analysis of discrete interferometric data. A typical optical ray is shown traversing an object field. The crosses indicate the sample points used in the truncated Whittaker-Shannon expansion, equation (8). 
so that equation (5) becomes a convenient interpolation series. When sample points and optical rays are specified as in Fig. 2, then $B_{l x}=1 /\left(2 l_{x}\right)$ and $B_{l y}=1 /\left(2 l_{y}\right)$, and equation (5) can be truncated and substituted into equation (4). As shown in detail in [17], this yields the following equation for $f\left(l_{x} m, l_{y} n\right)$, the approximate values of $f(x, y)$ at the sample points:

$$
\sum_{m=0}^{M-1} \sum_{n=0}^{N-1} W_{m n}\left(\rho_{i}, \theta_{j}\right) \bar{f}\left(l_{x} m, l_{y} n\right)=\Phi\left(\rho_{i}, \theta_{j}\right)
$$

$(M \cdot N)$, the number of sample points. The resulting over-determined system was solved in the least-meansquare sense using a numerical procedure developed by Golub [19]. Although no firm criteria for the number of measurements have been established, numerical simulations [17] indicate that increasing redundancy is usually much more important than dividing the field into a finer mesh of sample points. This limits the resolution of the reconstruction which can be attained using a fixed amount of data.

where

$$
W_{m n}\left(\rho_{i}, \theta_{j}\right)=\left\{\begin{array}{l}
\left(1+\tan ^{2} \theta_{j}\right)^{1 / 2} l_{x} \operatorname{sinc}\left[\frac{\rho_{i} \sec \theta_{j}+l_{x} m \tan \theta_{j}-l_{y} n}{l_{y}}\right] \text { for } 0 \leqslant\left|\tan \theta_{j}\right| \leqslant l_{x} / l_{y}, \\
\frac{\left(1+\tan ^{2} \theta_{j}\right)^{1 / 2} l_{y}}{\left|\tan \theta_{j}\right|} \operatorname{sinc}\left[\frac{\rho_{i} \sec \theta_{j}+l_{x} m \tan \theta_{j}-l_{y} n}{l_{x} \tan \theta_{j}}\right] \text { for } l_{y} / l_{x} \leqslant\left|\tan \theta_{j}\right| \leqslant \infty \\
l_{y} \operatorname{sinc}\left[\frac{\rho_{i}+m l_{x}}{l_{x}}\right] \text { for }\left|\tan \theta_{j}\right|=\infty .
\end{array}\right.
$$

Equations (6) and (7) form the basis of a scheme for inverting multi-directional interferometric data. A planar region within the field under study is considered to contain a rectangular network of sample points $(M \cdot N)$ in number, as in Fig. 2. Optical pathlengths, $\Phi\left(\rho_{i}, \theta_{j}\right)$, are then determined for a number, $(M \cdot N)$, of independent rays passing through the field in this plane. After noting the location and direction of each of these rays, the coefficients, $W_{m n}\left(\rho_{i}, \theta_{j}\right)$, of equation (6) can be evaluated using equation (7). This results in a system of $(M \cdot N)$ linear algebraic equations in the unknown values of $\bar{f}\left(l_{x} m, l_{y} n\right)$. After this system is solved, $f(x, y)$ is represented throughout the region by

$$
\begin{aligned}
\bar{f}(x, y)= & \sum_{m=0}^{M-1} \sum_{n=0}^{N-1} \bar{f}\left(l_{x} m, l_{y} n\right) \\
& \times \operatorname{sinc}\left[\left(x-l_{x} m\right) / l_{x}\right] \operatorname{sinc}\left[\left(y-l_{y} n\right) / l_{y}\right] .
\end{aligned}
$$

Ideally, an accurate determination of $f(x, y)$ can be made if the number of sample points, and of independent optical pathlength measurements, is equal to $4 B_{l x} B_{l y} L_{x} L_{y}$, which sometimes called the spacebandwidth product, SBWP. This assumes that $B_{l x}$ and $B_{l y}$ are accurately known, and that there is no system noise. In reality, the approximation that

$$
\int_{s} f(x, y) \mathrm{d} S=\int_{s} \bar{f}(x, y) \mathrm{d} S,
$$

experimental errors, and computational errors, all generate noise; furthermore, the bandwidths can at best be estimated. This generally leads to unacceptably poor reconstructions, particularly when the total angle of view is small, since the equations tend to be illconditioned. To alleviate these problems, redundant data must be used. In each experiment reported here, $\Phi$ was measured for a number of rays far in excess of

\section{EXPERIMENTAL INVESTIGATION}

Multi-directional holographic interferometry was used to measure the temperature field in the steady natural convective plume in the region above a heated rectangular surface submerged in water. Although no quantitative data were available with which these measurements could be compared some qualitative comparisons could be made with the flow visualizations of Husar and Sparrow [20] for this configuration. Two surfaces were used during the experiments. One had planar dimensions of $2.5 \times 1.9 \mathrm{~cm}$, and the other, $2.6 \times 1.3 \mathrm{~cm}$, giving aspect ratios of approximately 1.3 , and $2 \cdot 0$, respectively. Each heated plate was formed by two polished aluminum plates, $0.3 \mathrm{~cm}$ thick, between which an electrical heating element was sandwiched. The plate of aspect ratio 2.0 also had a small thermocouple embedded near its upper surface. A vertical plastic shroud extended down from the sides of the plate to minimize entrainment of heated fluid from below the plate. The heated surface under study was placed in a large glass tank containing distilled water. This points out a practical advantage of holographic interferometry; it is not necessary to use optically flat test section windows, as in classical interferometers. Because the holographic interferometer records only changes in optical pathlength between exposures, minor phase variations due to imperfect windows do not affect the fringe pattern sensibly. A differential thermocouple, with one junction in the plume, $1 \mathrm{~cm}$ above the surface, and the other junction in the ambient fluid, was included in the test section to provide an independent temperature measurement.

The optical apparatus was similar to that shown 


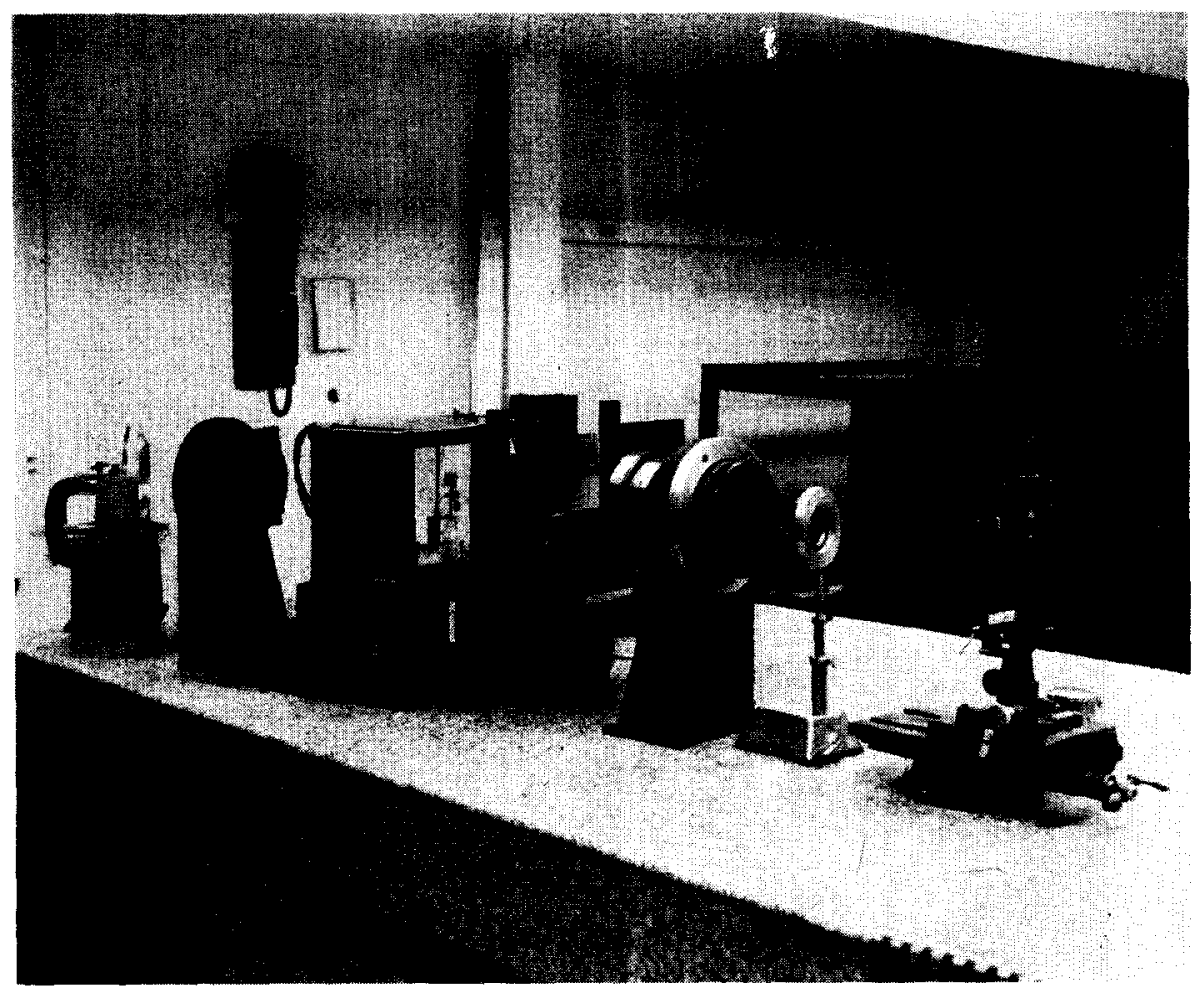

FIG. 3. The experimental system. The test section. hologram, and viewing system can be seen in the foreground.

schematically in Fig. 1. Most of the system can be seen in the photograph of Fig. 3. The light source was a $50 \mathrm{~mW}$ He-Ne laser (Spectra-Physics model 125). The object-and reference-beams were expanded and filtered using microscope objectives and pinhole filters. The object wave passed through an opal glass diffusing screen behind the test section. Holograms were recorded on $30.5 \mathrm{~cm}$ long Agfa 10 E70 photographic plates. Exposure times were on the order of $0 \cdot 1 \mathrm{~s}$. To assure mechanical stability, the interferometer and test section were assembled on a massive granite block.

The water in the tank was allowed to reach a quiescent state while standing in the air conditioned laboratory for several hours. The first holographic recording was made with the water in this state. The heated plate was then energized by a d.c. power supply at a rate of approximately $0.5 \mathrm{~W} / \mathrm{cm}^{2}$. After steady state was attained, the second holographic recording was made. The photographic plate was then developed, replaced in its holder, and illuminated with the reference beam.

The resulting interferogram was observed through a viewing system focused on a vertical plane near the heated plate. A spatial filter was placed in the back focal plane of this lens so that only optical rays traveling in one known direction contributed to the image.
Figure 4 shows two such views of one interferogram. The position of each light and dark fringe was noted by horizontally scanning the fringe pattern with an eyepiece fitted with crosshairs. The translation of the eyepiece was measured with a dial indicator. The optical system permitted a total angle of view of $30^{\circ}$, with one extreme viewing direction aligned with the centerline of the plate. Interferometric data was gathered in this manner for eight different directions within the $30^{\circ}$ angle of view. This data was reflected about the longitudinal centerline of the plate, under the assumption that it was a line of thermal symmetry. This led to an effective total angle of view of $60^{\circ}$ with approximately 200 individual optical pathlength measurements. Symmetry about the other centerline was not forced in the solution. The temperature field was then reconstructed in two different horizontal planes using the method described in the preceding section. Rectangular arrays of either twelve or sixteen sample points were used in computing the results reported here. Hence there was a very high degree of redundancy in the data. The selection of these mesh sizes was based on examination of the condition of the matrix $W_{i j}$ for various grids, and on experience with computer simulations $[15,17]$. Criteria for determination of optimum grid configurations and distribution of view- 
Fig. 4. Two views of a holographic interlerogram of the plume above the plate of aspect nitio 20

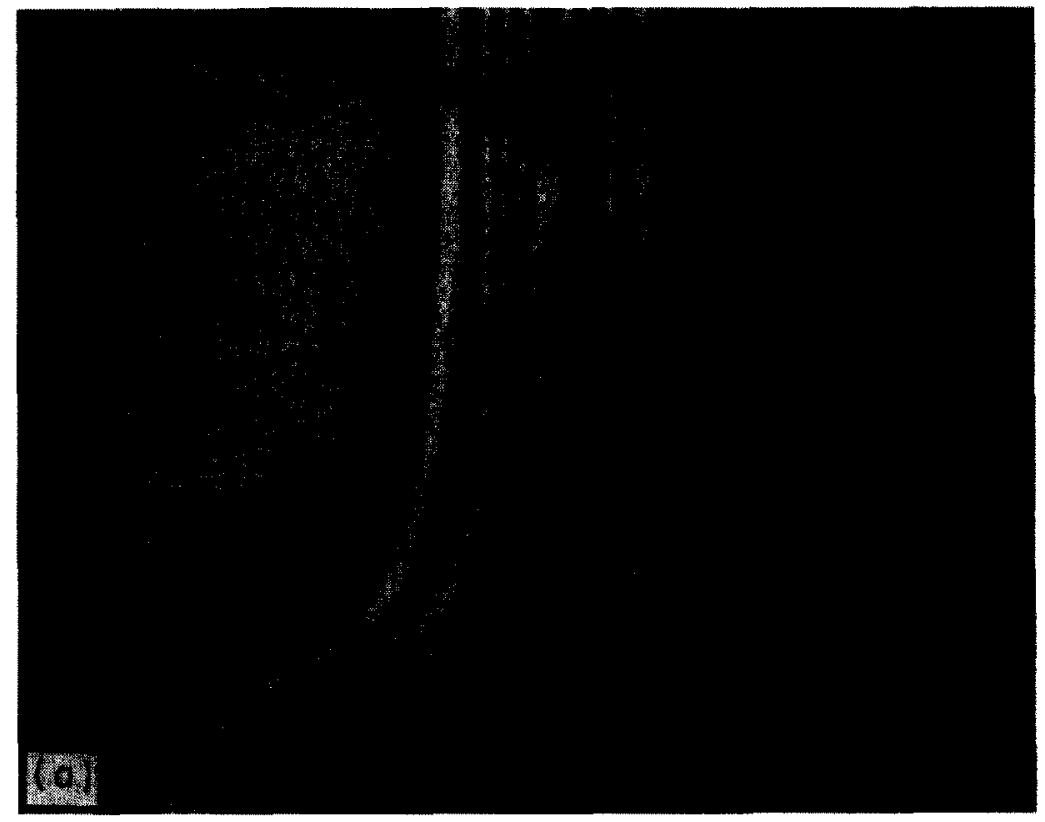

(a) The view along the axis of the plate.

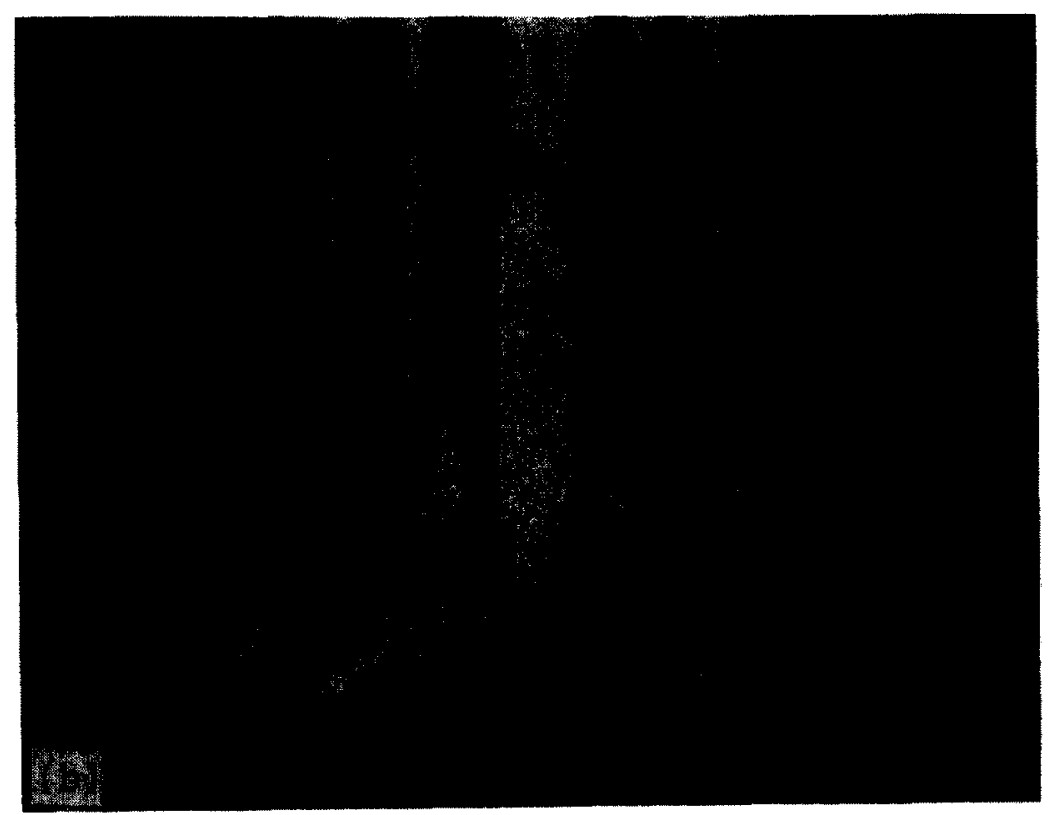

(b) The view along a direction 30 from the axis. The thermocouple is $1.05 \mathrm{~cm}$ above the plate. 


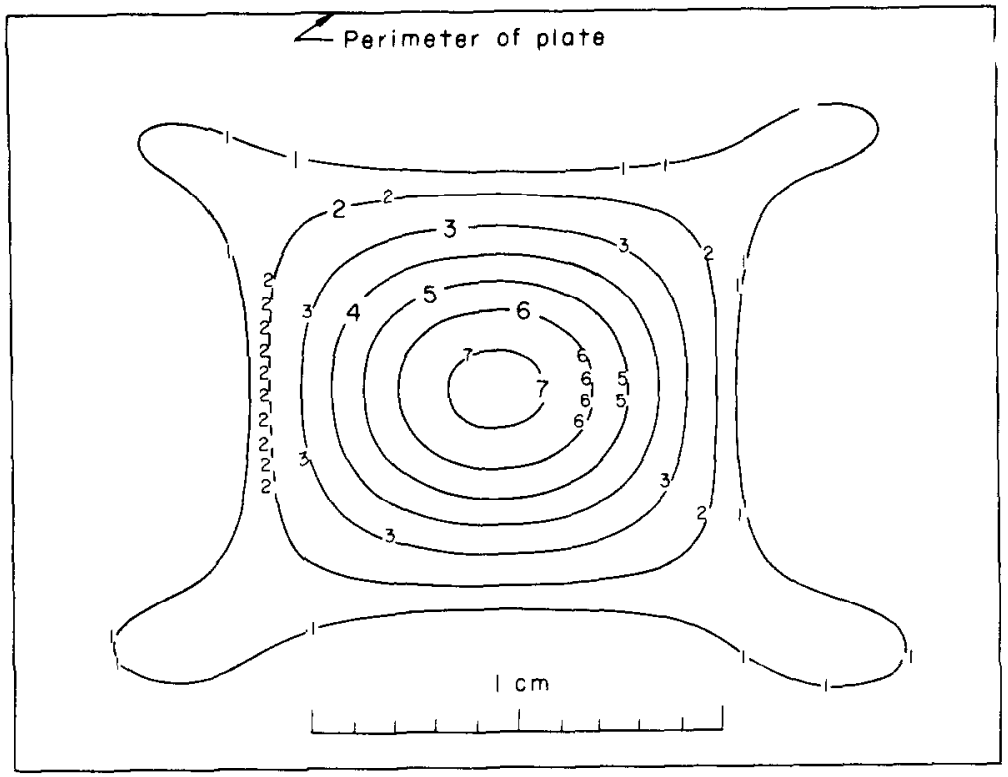

(a)

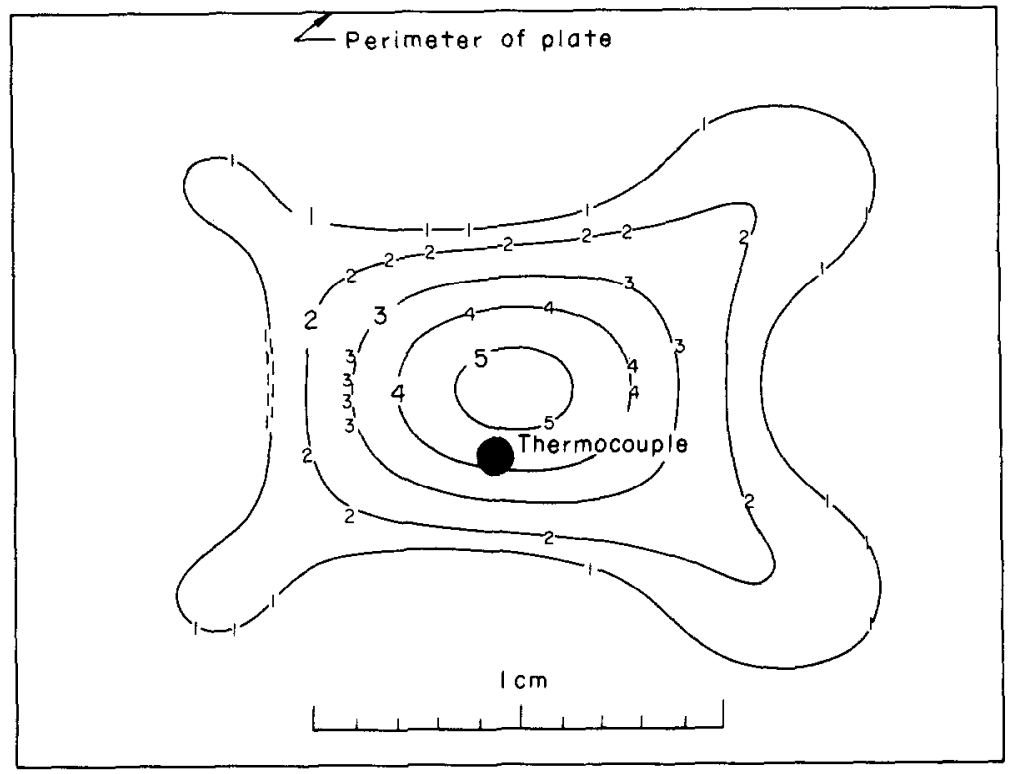

(b)

FIG. 5. Isothermal contours in horizontal planes above the plate of aspect ratio 1.3 . $R a \sim 9 \times 10^{5}$. (a) $0.5 \mathrm{~cm}$ above the plate. (b) $1.0 \mathrm{~cm}$ above the plate. The isotherms correspond to the following temperatures: $1\left(0 \cdot 3^{\circ} \mathrm{C}\right), 2\left(0 \cdot 6^{\circ} \mathrm{C}\right)$, $3\left(1 \cdot 1^{\circ} \mathrm{C}\right), 4\left(1 \cdot 6^{\circ} \mathrm{C}\right), 5\left(2 \cdot 1^{\circ} \mathrm{C}\right), 6\left(2 \cdot 6^{\circ} \mathrm{C}\right), 7\left(3 \cdot 1^{\circ} \mathrm{C}\right)$. 


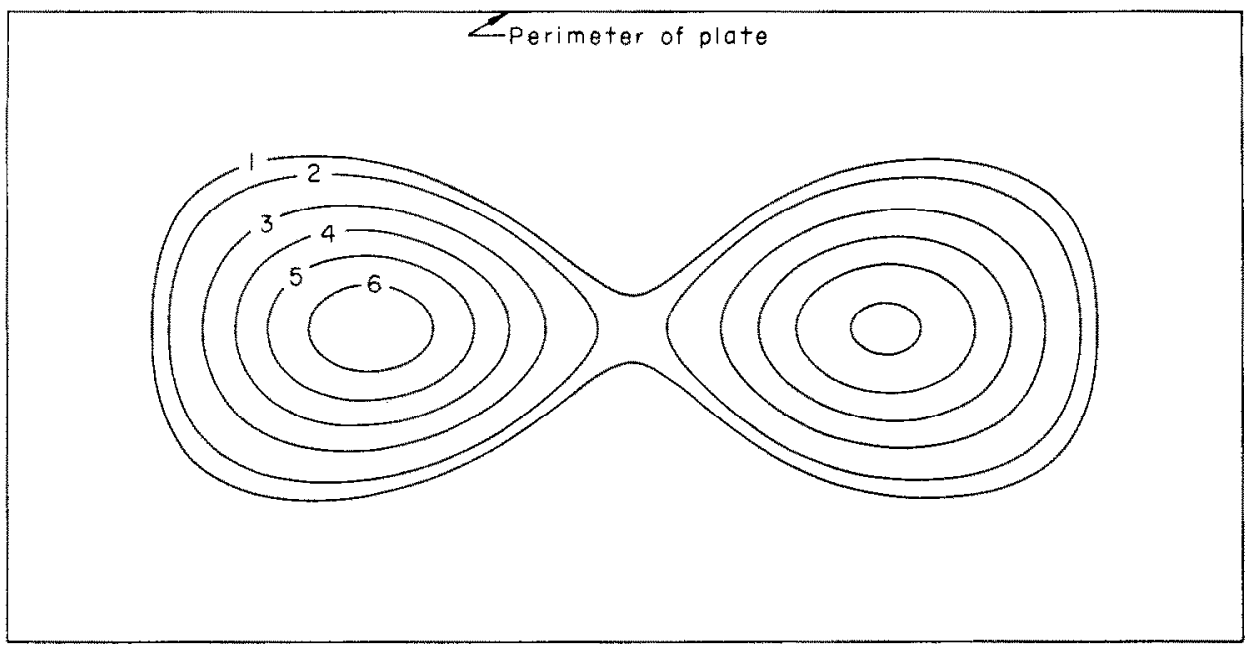

(a)

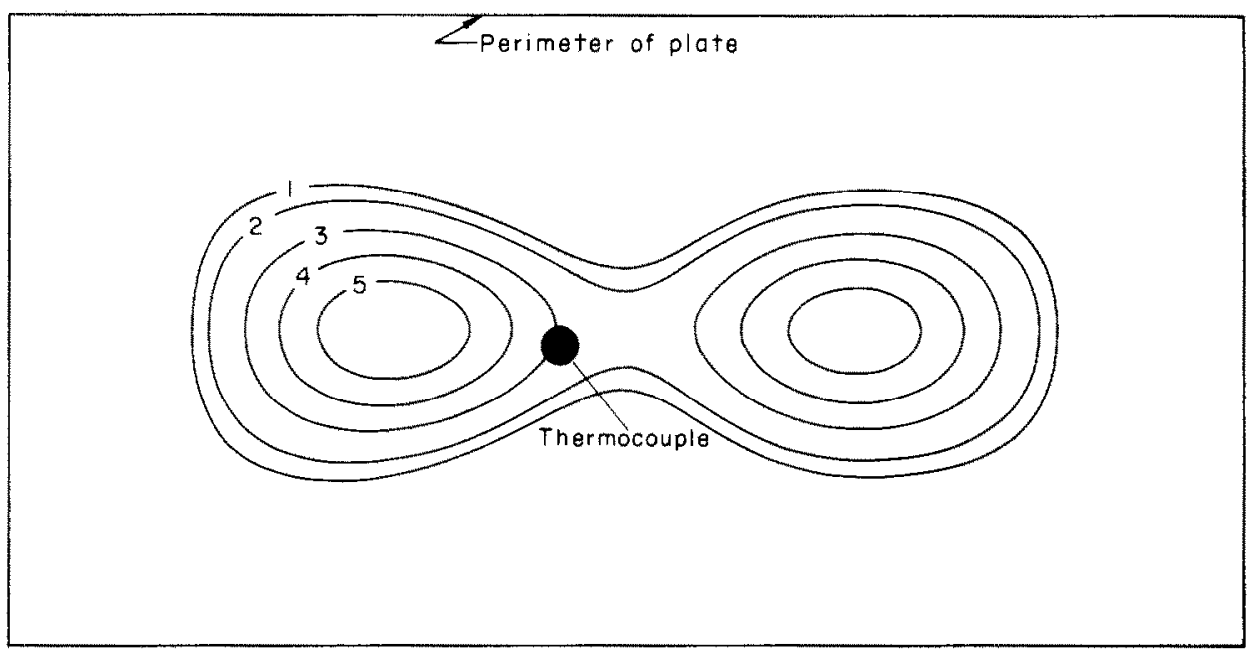

(b)

FiG. 6. Isothermal contours in horizontal planes above the plate of aspect ratio $2.0 . R a \sim 2 \cdot 8 \times 10^{5}$. (a) $0.8 \mathrm{~cm}$ above the plate. (b) $1.6 \mathrm{~cm}$ above the plate. The isotherms correspond to the following temperatures: $1(0 \cdot 3 \mathrm{C}), 2\left(0 \cdot 5^{\circ} \mathrm{C}\right), 3\left(1 \cdot 0^{\circ} \mathrm{C}\right), 4\left(1 \cdot 5^{\circ} \mathrm{C}\right), 5\left(2 \cdot 0^{\circ} \mathrm{C}\right), 6\left(2 \cdot 5^{\circ} \mathrm{C}\right)$.

ing angles are the subject of current research efforts.

The results of these experiments, in the form of computer-generated plots of isothermal contours, are presented in Figs. 5 and 6 . The Rayleigh number for this configuration was $R a \sim 9 \times 10^{5}$, where $R a=$ $g \beta\left(T_{s}-T_{\infty}\right) L^{3} / k v . T_{s}$ is the surface temperature of the plate and $L$ is the length of the shorter side of the plate. Figures $5(a)$ and (b) show the isotherms above the plate of aspect ratio 1.3 in planes which are $0.5 \mathrm{~cm}$ and $1.0 \mathrm{~cm}$ above the heated surface, respectively. The location of a thermocouple in the higher plane is indicated. This thermocouple indicated a temperature rise of $1.9^{\circ} \mathrm{C}$, which is clearly compatible with its location between the 1.6 and $2.1^{\circ} \mathrm{C}$ isotherms determined by interferometry. An interesting feature of these contours is the "fingers" extending toward the corners of the plate. Figures 6(a) and (b) show the isothermal contours at planes 0.8 and $1.6 \mathrm{~cm}$ above the heated surface having the higher aspect ratio of $2 \cdot 0$. For this configuration $R a \sim 2.8 \times 10^{5}$. This temperature field exhibits two maxima, rather than one occurring above the plate of aspect ratio 1.3 . There is no evidence of "fingers" near the corners; however, this is likely due 


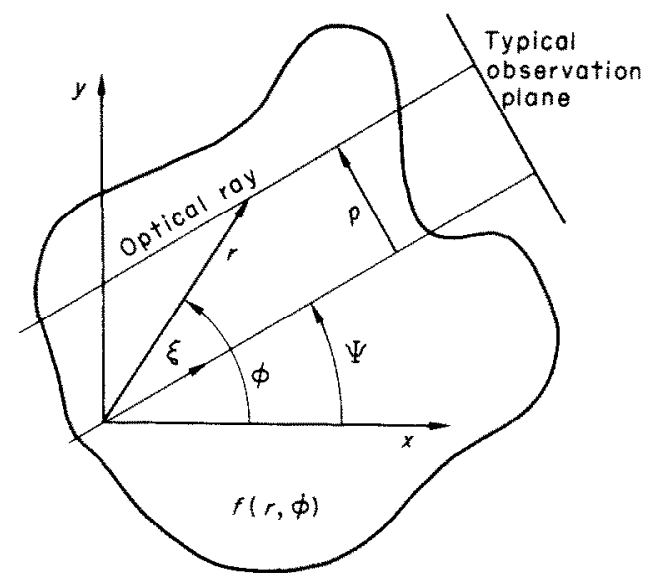

Fig. 7. Nomenclature for analysis of continuous interferometric data.

to insufficient temperature resolution in either the measurement or the plot. During this experiment, a thermocouple in the plume near the $1.6 \mathrm{~cm}$ plane indicated a temperature rise of $1.1^{\circ} \mathrm{C}$. Its position overlaps the $1.0^{\circ} \mathrm{C}$ isotherm determined by interferometry. Based on the thermocouple measurements, augmented by experience gained by computer simulation of experiments, and criteria dealing with the condition of the matrix $W_{m n}$ [15], it is estimated that the measurements reported here are accurate within about \pm 5 per cent of the maximum temperature rise.

\section{DISCUSSION}

The use of holographic interferometry, and data analysis techniques of the type presented here, greatly extends the class of experiments in which quantitative interferometry may be applied. Of course it shares certain inherent difficulties with all interferometric methods: gradients must be small so that refraction of light rays is negligible; diffraction limits the ability to make accurate measurements very close to solid boundaries; and it is not possible to discern whether fringe order (and therefore temperature) is increasing or decreasing as the interferogram is scanned. The latter problem can be aleviated if the experimenter has some knowledge of the structure of the field, or if simultaneous measurements arc made with a gradientsensitive technique such as shclieren photography. The sign of gradients could also be determined by introducing a linear phase shift of known sign in the object beam between exposures, and noting whether the number of fringes increases or decreases. Currently, the requirement of negligible refraction places a definite limitation on the applicability of interferometry, and must be considered as a criterion in the scaling of experiments.
Although limited in scope, the measurements presented here disclose certain interesting features of the developing plume above heated rectangular plates. A single column of heated fluid rose above the center of the plate of aspect ratio $1 \cdot 3$, while the isotherms surrounding this hot column formed "fingers" aligned with the bisectors of the corners of the plate. The thermal structure above the plate having a larger aspect ratio, $2 \cdot 0$, was different. Two heated columns, centered on the points of intersection of the bisectors of the corners of the plate were observed. These measurements are corroborated by the flow visualizations carried out by Husar and Sparrow [20]. They observed the flow adjacent to a horizontal heated plate to be partitioned by lines nearly coincident with the bisectors of the corners, and, in the central region, with the longitudinal centerline. The present study confirms that heated columns rise above these partitioning lines and persist in dominating the thermal structure of the plume for some distance above the plate. This is compatible with the form of flow suggested by Stewartson [21] for the fluid above a heated two-dimensional surface: a boundary layer originates at each edge of the plate; in these layers, fluid moves inward toward the center of the plate until the boundary layers collide. As a result of this collision, jets of heated fluid are ejected upward. It follows from this argument, and from the experimental observations, that flow adjacent to a heated surface, and the structure of the developing buoyant plume above it, are largely determined by the symmetries of the surface. An example of the importance of this characteristic is found in recent experiments of Oker [22], who has photographed the onset of boiling in freon 113, and liquid nitrogen, above heated rectangular plates of dimension $2.21 \times 2.49 \mathrm{~cm}$. If such plates have highly polished surfaces, the first few bubbles consistently appear near the intersections of lines of symmetry, which correspond to the hottest region in the plume shown in Fig. 6.

The only other measurements of three-dimensional temperature distributions above finite heated surfaces appear to be those of Weise [23] and Krause [24], who used large numbers of thermocouples. The present observations cannot be directly compared with these because unshrouded square plates on the order of 15-20 times larger than those in the present investigation were used.

Partitioning, and the corresponding plume structure have thus far been observed only near rather small plates (dimensions on the order of $1-10 \mathrm{~cm}$ ). Rotem and Claassen [25] have observed instability and breakdown of the horizontal boundary layer above larger heated surfaces. It is likely that this instability would diminish or destroy the partitioning effect over larger surfaces. Furthermore, several investigators have re- 
ported evidence of cellular convection superimposed on the large scale motions adjacent to heated surfaces. Hence the flow immediately above finite heated areas is in general quite complicated, and apparently, several different flow regimes must be defined. The nature of the flow adjacent to the heated surface is also reflected in the structure of the developing buoyant plume above it.

Acknowledgements-This work was supported in part by the National Science Foundation (Grant GK-41778) and the Office of Naval Research (Contract NR-048-618).

\section{REFERENCES}

1. W. Hauf and U. Grigull, Optical methods in heat transfer, Advances in Heat Transfer, edited by J. P. Hartnett and T. F. Irvine, Jr. Academic Press, New York (1970).

2. W. Alwang et al.. Item 1, Final Report, Pratt and Whitney Aircraft, PWA-3942 [NAVAIR (air-602) Contract] (1970).

3. M. V. Berry and D. F. Gibbs, The interpretation of optical projections, Proc. R. Soc. A314, 143-152 (1970).

4. A. M. Cormack, Representation of a function by its line integrals, with some radiological applications, J. Appl. Phys. 34, 2722-2727 (1963).

5. A. M. Cormack, Representation of a function by its line integrals, with some radiological applications $-I I, J$. Appl. Phys. 35, 2908-2913 (1964).

6. H. G. Junginger and W. van Haeringen, Calculation of thrce-dimensional refractive-index field using phase integrals, Opt. Comm. 5, 1-4 (1972).

7. M. H. Horman, An application of wavefront reconstruction to interferometry, Appl. Opt. 4, 333-336 (1965).

8. L. O. Heflinger, R. F. Wuerker and R. E. Brooks, Holographic interferometry, J. Appl. Phys. 37, 642-649 (1966).

9. W. Aung and R. O'Regan, Precise measurement of heat transfer using holographic interferometry, Rev. Scient. Instrum. 42. 1755-1759 (1971).

10. R. D. Matulka and D. J. Collins, Determination of three-dimensional density fields from holographic interferograms, J. Appl. Phys. 12, 11091119 (1971).

11. E. N. Leith and J. Upatnieks, Reconstructed wavefronts and communication theory, J. Opt. Soc. Am. 52, $1123-1130(1962)$.

12. R. J. Collier, C. B. Burckhardt and L. H. Lin, Optical Holography. Academic Press, New York (1971).

13. C. M. Vest and D. W. Sweeney, Holographic interferometry of transparent objects with illumination derived from phase gratings, Appl. Opt. 9, 2321-2325 (1970).

14. M. M. Butusov, Use of a matte scatterer in holographic interferometry, Soviet Phys.-Tech. Phys. 17, 325-328 (1972).

15. D. W. Sweeney, Measurement of three-dimensional temperature fields by holographic interferometry, Ph.D. dissertation, The Univ. of Michigan (1972).

16. C. D. Maldonado and H. N. Olsen, New method for obtaining emission coefficients from emitted spectral intensities-II. Asymmetrical sources, J. Opt. Soc. Am. 56, 1305-1313 (1966).

17. D. W. Sweeney and C. M. Vest, Reconstruction of threedimensional refractive index fields from multidirectional interferometric data. Appl. Opt. 12, 2649-2664 (1973).
18. D. P. Petersen and D. Middleton, Sampling and reconstruction of wavenumber-limited functions in $\mathrm{N}$ dimensional Euclidean spaces. Information and Control 5, $279-323(1962)$.

19. G. Golub, Numerical methods for solving linear least squares problems, Numer. Math. 7, 206-216 (1965).

20. R. B. Husar and E. M. Sparrow, Patterns of free convective flow adjacent to horizontal heated surfaces, Int. J. Heat Mass Transfer 11, 1206-1208 (1968).

21. K. Stewartson, On the free convection from a horizontal plate, Z. Ange'w. Math. Phys. 9, 276-282 (1958).

22. E. Oker, Transient boiling heat transfer in saturated liquid nitrogen and F113 at standard and zero gravity, Ph.D. Thesis, The Univ. of Michigan (1973).

23. R. Weise, Wärmeübergang durch freie Konvektion an quadratischen Platten, Forsch. Geb. IngWes. 6, 281-292 (1935).

24. W. Kraus, Temperatur- und Geschwindegkeitsfeld bei freier Konvektion um eine waagenechte quadratische Platte, Phys. Z. 41, 126-150 (1940).

25. Z. Rotem and L. Claassen, Natural convection above unconfined horizontal surfaces, J. Fluid Mech. 39 , 173-192 (1969).

26. P. D. Rowley, Quantitative interpretation of threedimensional weakly refractive phase objects using holographic interferometry, J. Opt. Soc. Am. 59, 14961498 (1969).

27. R. N. Bracewell, Strip integration in radio astronomy, Aust. J. Phys. 9, 198-217 (1956).

28. I. M. Gel'Fand, M. I. Graev and N. Ya. Vilenkin, Generalized Functions, Vol. 5. Academic Press, New York (1966).

29. F. John, Plane Waves and Spherical Means Applied to Partial Differential Equations. Interscience. New York (1955).

30. J. Radon, Uber die Bestimmung von Funktionen durch ihre Integralwerte längs gewisser Mannigfallegkeiten, Ber. Verh. Suchs. Akad. 69, 262-277 (1917).

\section{APPENDIX}

Inversion of Multi-Directional Interferometric Data

In multi-directional interferometry, the pathlength function is known for rays traversing the object field in several different directions. Under ideal circumstances in which it is known for all possible rays traversing the field, a formal solution to the problem of inverting the data is known. Its Fourier transfer was found by Rowley [26]; Berry and Gibbs [3], considering the analysis of X-ray shadowgraphs, also obtained this transform and inverted it to yield $f(r, \phi)$ as a functional of $\Phi$. Others have independently derived this relation $[2,6]$, and Bracewell [27] earlier analyzed a similar problem in radio astronomy. We wish to point out here that this solution can in fact be found by a straight forward application of the Radon transform.

The Radon transform can be defined by (cf. Gel'Fand et al. [28]):

$$
f(\xi, p)=\int f(x) \delta[p-(\xi, x)] \mathrm{d} x
$$

where $\mathrm{d} x=\mathrm{d} x_{1}, \ldots, \mathrm{d} x_{\mathrm{n}}$ is a volume element in a real affine space of $n$ dimensions, $\delta$ is the Dirac delta function, and where $\left(\xi_{1}, x\right)=\xi_{1} x_{1}+\ldots+\xi_{n} x_{n}=p$ defines a hyperplane of dimension $(n-1)$. For a space of even dimension, which is of 
interest in the present problem, the inverse Radon transform is

$$
\begin{aligned}
f(x)= & \frac{(-1)^{n / 2}(n-1) !}{(2 \pi)^{n}} \\
& \times \int_{\Gamma}\left[\int_{-\infty}^{\infty} f(\xi, p)\{(p-\xi, x)\}^{-n} \mathrm{~d} p\right](0)(\xi)
\end{aligned}
$$

where $\omega$ is a differential form expressible as

$$
\omega(\xi)=\sum_{k=1}^{n}(-1)^{k-1} \xi_{k} \mathrm{~d} \xi_{1} \ldots \mathrm{d} \xi_{k-1} \mathrm{~d} \xi_{k+1} \ldots \mathrm{d} \xi_{n},
$$

and where $\Gamma$ is any closed surface enclosing the point $=0$ in the $\xi$ space.

To apply these general relations to the specific problem of interpreting multi-directional interferograms, the nomenclature indicated in Fig. 7, which is identical to that used by Berry and Gibbs [3], is introduced. This figure shows a typical optical ray traversing the field $f(\mathbf{r})$ and impinging on the observation plane, where its optical pathlength $\Phi(\psi, p)$ is measured. The optical pathlength is

$$
\Phi(\psi, p)=\int f(\mathbf{r}) \delta[p-r \sin (\phi-\psi)] \mathrm{d} \mathbf{r} .
$$

which is seen to be the radon transform. equation (9). for the special case $n=2$, and where the $(n-1)$ dimensional hypersurface is simply the line defined by $r \sin (\phi-\psi)=p$. It follows that $x_{1.2}=(x, y)$ and $\xi_{1.2}=(-\sin \psi, \cos \psi)$, and further that $\omega=\xi_{1} \mathrm{~d} \xi_{2}-\xi_{2} \mathrm{~d} \xi_{1}$, is simply

$$
\omega=\mathrm{d} \psi \text {. }
$$

Finally, if $\Gamma$ is chosen to be the unit circle, application of the inverse Radon transform, equation (10), yields

$$
f(r, \phi)=\frac{-1}{4 \pi^{2}} \int_{-\pi}^{n} \mathrm{~d} \psi \int_{-\infty}^{\infty} \frac{\Phi(\psi, p) \mathrm{d} p}{[p-r \sin (\phi-\psi)]^{2}} .
$$

Since $p$ takes on both positive and negative values, this can be written as

$$
f(r . \phi)=\frac{-1}{2 \pi^{2}} \int_{-\pi / 2}^{\pi \cdot 2} \mathrm{~d} \psi \int_{-\infty}^{\infty} \frac{\Phi(\psi, p) \mathrm{d} p}{[p-r \sin (\phi-\psi)]^{2}} .
$$

Based on this discussion. it can be stated that the fringe patterns formed when an object $f(r, \phi)$ is inserted into a multi-directional interferometer display contours of the Radon transform of $f(r, \phi)$. Conversely, $f(r, \phi)$ can be reconstructed by taking the inverse Radon transform of the interferometric data. If the integral over $p$ in equation (15) is evaluated by integration once by parts, assuming that ( $\rightarrow 0$ as $p \rightarrow \pm \infty$. the relation which was developed by Berry and Gibbs [25] results:

$$
f(r, \phi)=\frac{1}{2 \pi^{2}} \int_{-\pi / 2}^{\pi / 2} \mathrm{~d} \psi \int_{-\infty}^{\infty} \frac{(\partial \Phi / \partial p) \mathrm{d} p}{r \sin (\phi-\psi)-p}
$$

where

$$
\begin{array}{rrrl}
-x & \leqslant p \leqslant \infty & -\pi / 2 & \leqslant \psi \leqslant \pi / 2 \\
-x \leqslant r \leqslant \infty & 0 \leqslant \phi \leqslant \pi .
\end{array}
$$

Alternative forms of the Radon transform and its inversion formula are given by John [29], who points out that Radon [30] was the first to consider the general problem of synthesizing a function from the values of its integrals over a collection of planes.

\title{
MESURE PAR INTERFEROMETRIE HOLOGRAPHIQUE DU CHAMP TRIDIMENSIONNEL DE TEMPERATURE PRES DES SURFACES CHAUFFEES
}

\begin{abstract}
Résumé-L'holographie optique peut être utilisée pour des mesures interférométriques multidirectionnelles, lesquelles fournissent un moyen de détermination des champs disymétriques et tridimensionnels de température ou de densité dans les fluides. Si les mesures continues sont possibles dans un angle de vue de $180^{\circ}$, le champ de température ou de densité est égal à la transformée inverse Radon des mesures. On présente une procédure. par résolution limitée numérique, de reconstruction du champ à partir de données discrètes collectées dans un angle de vue limité. La technique de l'interféromètrie holographique a été utilisée pour dresser la carte des contours isothermes dans le panache convectif au dessus des surfaces chaudes, horizontales et rectangulaires. On a trouvé que la structure thermique du panache est fortement influencée par le partage de l'écoulement adjacent à la surface, le long des lignes de symétrie géométrique.
\end{abstract}

\section{DIE MESSUNG VON DREIDIMENSIONALEN TEMPERATURFELDERN ÜBER BEHEIZTEN OBERFLÄCHEN MIT HILFE DER HOLOGRAPHISCHEN INTERFEROMETRIE}

Zusammenfassung-Die optische Holographie kann zur Aufzeichnung interferometrischer Daten dienen, die eine Grundlage zur Messung dreidimensionaler asymmetrischer Temperatur- oder Dichtefelder in Fluiden liefern. Wenn die optische Weglänge über einen Winkel von $180^{\circ}$ kontinuierlich gemessen wird, dann zeigt es sich, daß das Temperatur- und Dichtefeld gleich der umgekehrten Radon-Umformung der Meßwerte ist. Es wird ein Verfahren zur Berechnung des Aufbaus des Feldes aus begrenzten Elementen mit Hilfe einzelner Meßwerte angegeben, die für einen beschränkten Winkel aufgenommen sind. Die holographische Interferometrie diente zur Darstellung der Isothermen in dem sich ausbildenden Konvektionsstreifen über beheizten. horizontalen. rechteckigen Oberfächen. Es ergab sich, daß der thermische Aufbau des sich ausbildenden Streifens sehr stark durch die Aufteilung der Strömung beeinflußt wurde, die an die Oberfläche entlang geometrischer Symmetrielinien angrenzt. 
ИЗМЕРЕНИЯ ТРЁХМЕРНЫХ ТЕМПЕРАТУРНЫХ ПОЛЕЙ НАД НАГРЕТЫМИ ПОВЕРХНОСТЯМИ МЕТОДОМ ГОЛОГРАФИЧЕСКОЙ ИНТЕРФЕРОМЕТРИИ

Аннотация - Оптическую голографию можно использовать для регистрации многоцелевых интерферометрических данных, так как она позволяет измерять трёхмерные, асимметрические поля температур или плотности в жидкостях. Показано, что при наличии данных вдоль непрерывной оптической плины пути под углом обзора более $180^{\circ}$ температурное поле или поле плотности определяется обратным преобразованием Радона от этих данных. Представлен метод расчёта для реконструкций поля с ограниченным разрешением при помощи дискретных данных, полученных под ограниченным углом обзора.

Техника голографической интерферометрии использовалась для нанесения изотермических контуров при развитии конвективного ореола над нагретыми, горизонтальными, прямоугольными поверхностями. Найдено, что разделение прилегающего к поверхности потока вдоль линии геометрической симметрии оказывает сильное влияние на термическую структуру развивающегося ореола. 